\title{
Rare Case Report on Emamectin Benzoate Poisoning in Buffaloes
}

\section{Sudhakara Reddy $\mathrm{B}^{1}$ and Sivajothi S2* $^{2 *}$}

${ }^{1}$ Assistant Professor (Veterinary Medicine), Department of Veterinary Clinical Complex, Sri Venkateswara Veterinary University, India

${ }^{2}$ Assistant Professor, Department of Veterinary Parasitology, Sri Venkateswara Veterinary University, India

*Corresponding author: Sivajothi S, Assistant Professor, Department of Veterinary Parasitology, College of Veterinary Science, Sri Venkateswara Veterinary University, Proddatur, 516360, India, Email: sivajothi579@gmail.com

\section{Abstract}

Emamectin benzoate is a macrocyclic lactone which is commonly used as pest control in agriculture and indiscriminate use of these compounds causes toxicity in the livestock. Two buffaloes were reported to be had a history of accidental ingestion of emamectin benzoate mixed solution and they showed disorientation, circling, incoordination, salivation, nasal discharges and shivering. Animals were treated with atropine sulfate, fluid therapy with vitamin supplementation and oral laxatives. Adult buffalo was recovered from the toxicity by the fifth day of therapy but buffalo calf was died by the second day of therapy.

Keywords: Buffalo, Calf, Emamectin benzoate, Poisoning

\section{Introduction}

Pesticides are used in large amounts in agriculture and toxicity of the chemicals was increasing daily in the animals. Different types of avermectin group of drugs are used to treat the external and internal parasites of animals including human. But, emamectin benzoate used against various lepidopteran pests and is being developed for use on major field crops and vegetables [1]. Present communication reports the rare case of emamectin benzoate toxicity in buffaloes.

\section{Case History and Clinical Observations}

One adult buffalo and the calf were referred with the complaint of accidental ingestion of water mixed with emamectin benzoate solution (5\% EC mixed around 5 litres of water). Both the animals started incoordination and salivation after six hours of ingestion of water. Adult buffalo showed the dullness, salivation, nasal discharges, shivering, incoordination and dry muzzle (Figure 1). Calf showed the ataxia, hypermetria, disorientation, circling and severe salivation. Elevated rectal temperature, 
increased heart rate and respiratory rate, congested mucus membrane, rumen atony and abdominal straining were noticed in both the animals.

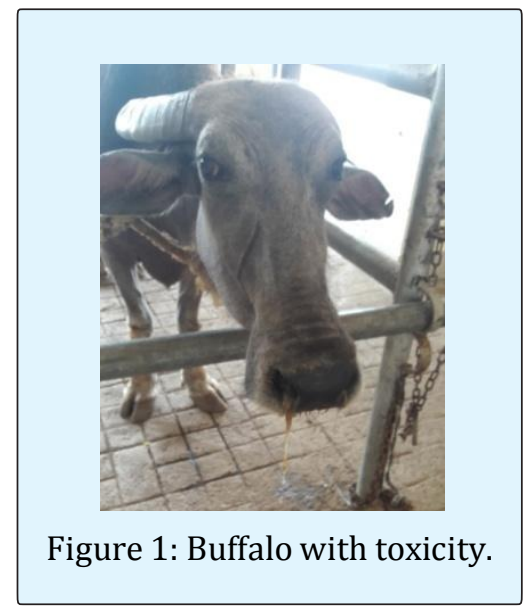

\section{Treatment and Discussion}

Both the animals were administered with inj. 5\% Dextrose Normal Saline (20 ml/kg body weight, IV, BID), inj. B complex (10 ml, IV), inj. atropine sulfate (@ 0.5 $\mathrm{mg} / \mathrm{kg}$ body weight, one fourth was given i/v and remaining was given $\mathrm{s} / \mathrm{c}$; Half of the total dose was repeated after $6 \mathrm{hrs}$ ) along with the laxative and detoxicant powder which contains magnesium sulfate (Bovilax, 500 gm PO, 100 gm BID in calf). Adult buffalo showed improvement after four hours of administration and treatment was repeated for three days by monitoring of the animals [2].

By the third day adult buffalo started feed intake and free from salivation. Shivering was noticed until the fourth day and it was completely free from toxicity signs after the fifth day. But, the calf died after the second day of presentation. In the present case, straining of the abdomen was noticed and it might be due to mucosal irritation caused by the chemicals. Recorded nervous signs in the present buffaloes were due to depression of central nervous system caused by emamectin.

Emamectin benzoate is a 4'-deoxy-4'-epi-methyl-amino benzoate salt of avermectin B1 (abamectin), which is similar structurally to natural fermentation products of Streptomyces avermitilis. Emamectin benzoate is being developed as a newer broad-spectrum insecticide for vegetables as pest control. It showed high-affinity towards GABA receptors and a consequent increase in membrane chloride ion permeability [3]. It had wide margin of safety in mammals due to the lack of glutamategated chloride channels in mammals, low affinity of avermectins and their inability to readily cross the blood-brain barrier. No specific antidote was there for emamectin benzoate intoxication in mammals. It was gastric lavage, administration of activated charcoal while treating with antibiotics was successful in humans. Recently it was reported in a buffalo with its successful management [4].

Toxicity of the emamectin benzoate was more in the calf than comparing with the adults. In the present study calf not responded with the treatment and died on the second day of therapy. Adult buffalo was responded to the therapy after five days. No available specific antidote for the emamectin benzoate toxicity in animals. Here adult buffalo was managed symptomatically with fluid therapy, gastric laxatives which will reduce the toxic effect of emamectin benzoate.

\section{Summary}

Present communication record on the rare emamectin benzoate toxicity in buffaloes.

\section{References}

1. Parsaeyan E, Saber M, Bagheri M (2013) Toxicity of emamectin benzoate and cypermethrin on biological parameters of cotton bollworm, Helicoverpa armigera (Hubner) in laboratory conditions. J Crop Protect 2: 477-485.

2. Constable PD, Hinchcliff KW, Done SH, Grunberg, W (2017) Veterinary Medicine - A Textbook of the Diseases of Cattle, Horses, Sheep, Pigs and Goats, $11^{\text {th }}$ (Edn.), Saunders, USA.

3. Yen TH, Lin LJ (2004) Acute poisoning with Emamectin benzoate. J Toxicol Clin Toxicol 42(5): 657-661.

4. Jadhav RK, Bhikane AU, Kushwaha N, Jadhav AS (2017) Management of rare case of emamectin benzoate poisoning in a buffalo. Buffalo Bulletin 36(4): 717-718. 